\title{
Challenging management of congenital bilateral radial club hand: A case report
}

\author{
Abdulrahman Alhaji Mahmud ${ }^{1,2}$, Muhammad Kabir Abubakar ${ }^{1}$, Musa Adamu Kabir ${ }^{1}$, \\ Mohammed Inuwa Ismail ${ }^{1}$, Muslimat Ajibola Alada ${ }^{1}$, Bashir Bello ${ }^{1,3^{*}}$ \\ ${ }^{1}$ Department of Surgery, Aminu Kano Teaching Hospital, Kano, Nigeria; *Corresponding Author: nurubash@yahoo.com \\ ${ }^{2}$ Department of Surgery, Faculty of Medicine, Bayero University, Kano, Nigeria \\ ${ }^{3}$ Department of Physiotherapy, Faculty of Medicine, Bayero University, Kano, Nigeria
}

Received 21 November 2013; revised 20 December 2013; accepted 7 January 2014

Copyright (C) 2014 Abdulrahman Alhaji Mahmud et al. This is an open access article distributed under the Creative Commons Attribution License, which permits unrestricted use, distribution, and reproduction in any medium, provided the original work is properly cited. In accordance of the Creative Commons Attribution License all Copyrights (C) 2014 are reserved for SCIRP and the owner of the intellectual property Abdulrahman Alhaji Mahmud et al. All Copyright (C) 2014 are guarded by law and by SCIRP as a guardian.

\section{ABSTRACT}

Congenital radial club hand $(\mathrm{CRCH})$ is a terminal deficiency characterized by the radial deviation of the hand, marked shortening of the forearm, and generalized underdevelopment of the extremity with an incidence rate of 1 per 100,000 live births. Both sexes are nearly or equally affected. Challenges that the disease poses to the patient are multifaceted, ranging from medical, social, cosmetic and functional issues which also are the multidimensional treatment modalities. We report a case of a 2-month-old baby with the severe case of bilateral $\mathrm{CRCH}$. The patient had the centralization of the left ulna with $\mathrm{K}$ wire stabilization. About $160^{\mathrm{d}}$ of correction was achieved. He did well and was discharged after two weeks at the orthopedic clinic for follow-up. Congenital radial club hand though uncommon may be amenable to surgery. Centralization is still the treatment of choice in severe cases and early intervention will offer a better outcome.

\section{KEYWORDS}

\section{Congenital Radial Club Hand; Centralization; Early Intervention}

\section{INTRODUCTION}

Congenital radial club hand (CRCH) also called radial dysplasia is an uncommon longitudinal deficiency of the radial part of the arm. It could be bilateral or unilateral and could also be partial or complete. Incidence is 1 per 100,000 live births. Both sexes are equally affected. Its challenges are multifaceted, ranging from medical, social, cosmetic and functional. The possible associations with other anomalies like, renal and cardiovascular or VACTERYL deformities also may make the management involve other specialties and may delay intervention.

Despite several treatment modalities, late presentation, local beliefs, the paucity of equipment, and cost of treatment may equally limit the choice of intervention and render poor prognosis.

\section{CASE REPORT}

This is a case of a two month old male child who was brought to the orthopedic clinic by his mother with complaint of deformity of both upper limbs noticed at birth. There was no deformity in the lower limbs. No other gross malformation was noted.

The pregnancy, birth and neonatal histories were uneventful. He is the last of seven siblings in a monogamous family.

He is on breastfeeds. His parents are not genetically related. The mother is 30 years and the father is 42 years old and they are of low income class.

Examination revealed, a $6 \mathrm{~kg}$ male child who was otherwise healthy looking. Examination of the musculoskeletal system revealed Figures 1(a) and (b) shortened right upper limb with absent elbow creases, fixed extension of the elbow. Passive range of movement was 0 - 1 degrees. There was radial deviation of about 90 degrees of the hand at the wrist with lobster deformity of the hand.

The left upper limb was also shortened with absent elbow crease and fixed extension deformity. Range of movement was 0 - 30 degrees. There was radial deviation of hand of about 70 degrees at the wrist. The thumb was absent.

Remaining parts of the musculoskeletal system are normal. Other systems were essentially normal. 


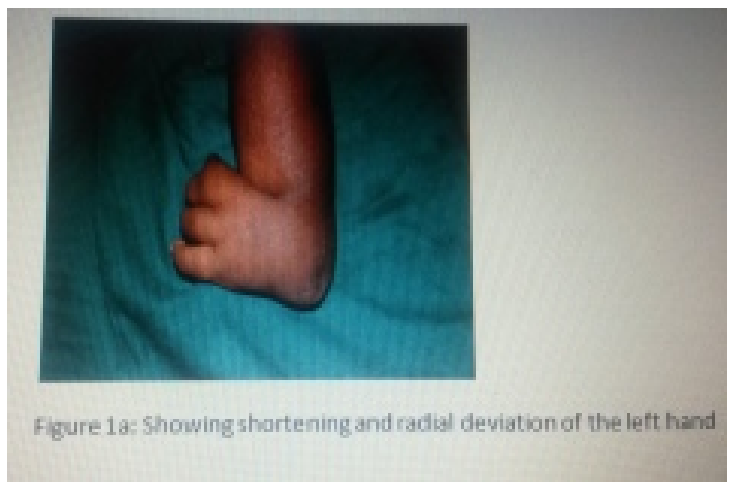

(a)

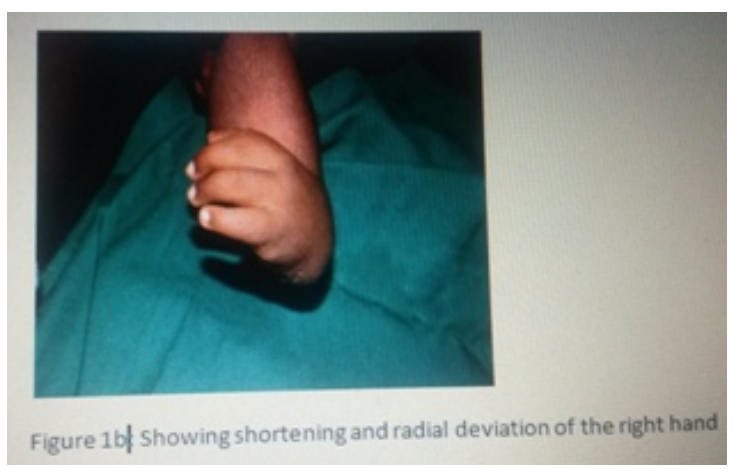

(b)

Figure 1. (a) Showing shortening and radial deviation of left hand; (b) Showing shortening and radial deviation of the right hand.

X-rays of both upper limbs (Figures 2 and 3) showed bilateral absence of radius with medial deviation of the hand. There was deficiency of some metacarpal bones.

Echocardiogram-showed a $5 \mathrm{~mm}$ defect in the membranous atria septum.

Abdominal ultrasound and IVU-showed right renal agencies.

Full blood count showed platelet of $127 \times 10^{9} \mathrm{per} / \mathrm{ml}$. The patient was referred to the cardiothoracic surgeon and urologist for further review.

He was assessed and placed on Aldactone and Frusemide by the cardiothoracic surgeon and urologist for further review. The urologist, hematologist and cardiothoracic surgeon certify the patient fit for surgery. Meanwhile, the patient was also commenced on physiotherapy for both elbow and hand. There was significant improvement on the elbow range of motion. The patient had centralization of the left ulna with K-wire stabilization. About $160^{\mathrm{d}}$ of correction was achieved (See Figure 4). He did well and was discharge after two weeks to the orthopedic clinic for follow up in clinic. He is also being followed up by cardiothoracic surgeon and urologist.

\section{DISCUSSION}

Congenital radial club hand $(\mathrm{CRCH})$ is a well recog-

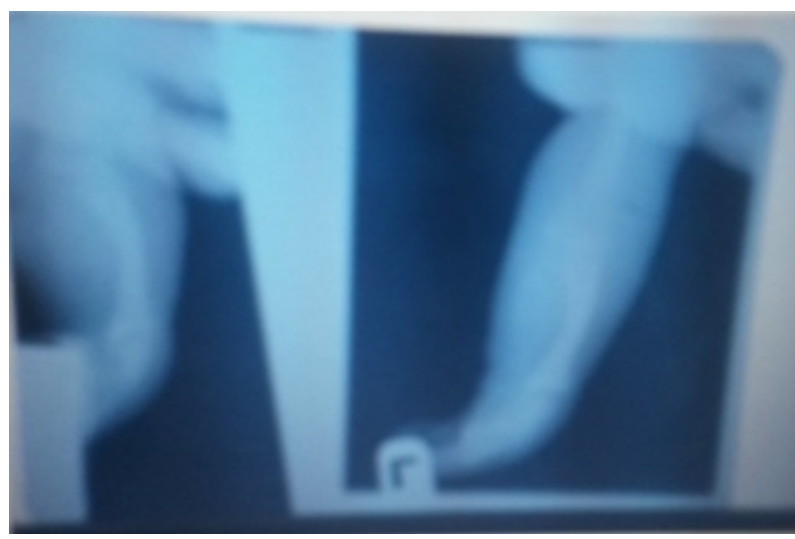

Figure 2. X-ray of the left upper limb showing absence of the radius with medial deviation of the hand.

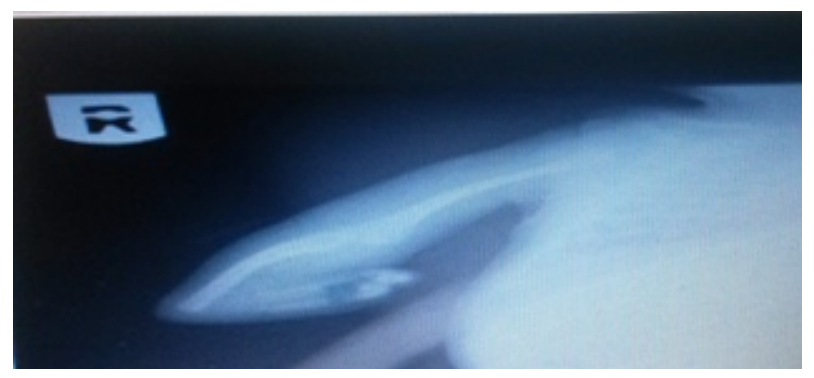

Figure 3. X-ray of the right upper limb showing absence of the radial bone with medial deviation of the hand.

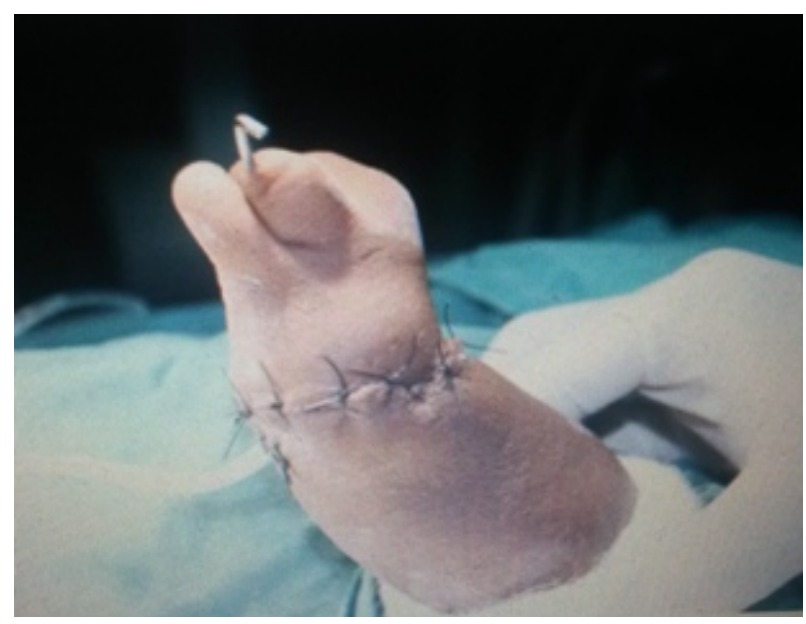

Figure 4. Post operative correction of medial deviation of the left hand.

nized congenital deformity characterized by hypoplasia of the bones and soft tissues on the radial aspect of the forearm and hand [1-3]. Above features are also typical to our patients.

$\mathrm{CRCH}$ is an uncommon congenital anomaly. It is a longitudinal deficiency along the preaxial or the radial aspect of the upper extremity. It includes a wide spectrum of disorders that encompass an absent thumb, thumb hypoplasia, a thin first metacarpal and an absent 
radius [1]. The frequency of this anomaly is between $1: 30,000$ to $1: 100,000$ live births. The radial deficiency is bilateral in $50 \%$ of the cases and slightly more common in males than in female [2]. Several theories have been postulated as the cause of the disease, like maternal drug exposure, compression of the uterus and vascular injury, but current theory relates the aetiology of the radial club hand to the Apical Ectodermal Ridge (AER) [3]. Kumar and Sumar explained that AER is a thickened layer of ectoderm that directs the differentiation of the underlying mesenchymal tissue and limb formation. They observed that removal of a portion of AER in chick embryos has produced anomalies which are similar to the radial club hand. Therefore, a defect of AER is the most probable cause of the radial club hand.

Typical deformities include forearm shortening, radial deviation of the wrist and hypoplasia of the thumb [4]. About $40 \%$ of patients with unilateral club hand and 27\% with bilateral club hand have associated with congenital anomalies involving cardiac, genitourinary, skeletal and hematopoietic system [4]. The prominent syndromes associated with RCH include: Holt-Oram syndrome thrombocytopenia-absent radius (TAR) syndrome VACTERL syndrome and Fanconi anemia [4]. This is also true to our patients who have the bilateral radial deficiency with the absent thumb and the small atrial septal defect.

Treatment modalities of this condition range from stretching cast to soft tissue procedures to the use of multiple corrective osteotomies [4]. Conservative management is recommended in mild cases, while surgical intervention is recommended in severe forms [4]. Our patients had a severe form, so had the surgical intervention.

Treatment goals include the creation of a stable centralized and functional hand, maintenance of mobile and stable wrist and preservation of longitudinal forearm growth [5].

Centralization procedures are the most common method of treatment [5] which our patients had. But they are associated with the high recurrence rate and the potential injury to the distal ulna physics with consequent decrease in the forearm growth [5].

Some authors advocate the distraction with the external fixation prior to the centralization. This has been found to reduce the incidence of the deterioration in the ulnar growth following the procedure.

Patients with residual deformity following centralization have also been treated with the ilizarov method to correct bowing of the ulnar and recurrence of the deformity.

The use of osteotomies with multiaxial corrective fixator seems to be a good alternative with fewer associated complication rates [1]. Our patients have not had any form of external fixation before or after the centralization nor has he had corrective osteomies.
Vacularized metatarsophalangeal joint transfer is a new concept in the management of radial club hand which has the satisfactory long-term effect and the lower recurrence rate [5,6], though the patient may require corrective osteotomy during puberty due to ulnar bowing [5]. The procedure is however demanding and it is recommended that it should be performed in a dedicated microsurgical centre with adequate tissue transfer experience [6]. There is no microsurgical centre in our hospital.

It is recommended that the correction of radial club hand should be staged; first, centralization of the wrist and second, lengthening of ulnar and correction of angular deformity with ilizarov method [7]. We have achieved the $1^{\text {st }}$ stage.

In a study by Clark et al. in 1998, 7 out of 11 patients with congenital absence of the thumb also had radial club deformity. No case of lobster deformity was reported [8].

Tenkir and Teshome in 2010 reported a case of Goltz syndrome with skeletal anomalies including lobster deformity of the left hand with no associated radial club [9].

A case of isolated unilateral radial club hand was reported by Salati and Rabah [3]. Shariatzedeh et al. reported that centralization still can be a standard procedure in treatment of patients with radial club hand with acceptable results with $60 \%$ correction and loss of correction in long term of 54\% [4].

In a study by Menelaus MB, centralization of ulnar followed by triceps muscle transfer in patients with radial club hand with the absence of the biceps muscle gave sufficient improvement in appearance even if function was not much improved [10]. Outcome of pollicisation of the index finger was better in those without associated radial club [10].

The presence of a fixed extension deformity at the elbow posed a challenge in achieving the full function of the corrected left upper limb.

Having achieved a reasonable range of wrist and finger movement on the left, six month post-operatively, the parents are demanding surgery on the right hand despite being told that in the long run the functional outcome is poor.

Congenital radial club hand though uncommon may be amenable to surgery. Early intervention in the presence of flexible elbows offers a better outcome. Centralization is still the treatment of choice.

\section{REFERENCES}

[1] Bhat, S.B., Kamath, A.F., Sehgal, K., Horn, B.D. and Hosalkar, H.S. (2009) Multi-axial correction system in the treatment of radial club hand. Journal of Children's Orthopaedics, 3, 493-498. 
http://dx.doi.org/10.1007/s11832-009-0196-3

[2] Shariatzadeh, H., Jafari, D., Taheri, H. and Mazhar, F.N. (2009) Recurrence rate after radial club hand surgery in long term follow up. Journal of Research in Medical Sciences, 14, 179-186.

[3] Kumar, M.K. and Sumar, S.K. (2011) Radial club hand: A Neglected case. Journal of Clinical and Diagnostic Research, 5, 1458-1460

[4] Salati, S.A. and Rabah, S.M. (2010) Congental isolated right radial club hand. Libyan Journal of Medicine, 5.

[5] de Jong, J.P., Moran, S.L. and Vilkki, S.K. (2012) Changing paradigms in the treatment of radial club hand: Microvascular joint transfer for correction of radial deviation and preservation of long-term growth. Clinics in Orthopedic Surgery, 4, 36-44. http://dx.doi.org/10.4055/cios.2012.4.1.36

[6] Vikki, S.K. (2008) Vascularized metatarsophalangeal joint transfer for radial hypoplasia. Seminar in Plastic Surgery, 22, 195-212.
[7] Kabawata, H., Shibata, T., Masatomi, T. and Yusui, N., (1998) Residual deformity in congenital radial club hands after previous centralization of the wrist, ulnar lengthening and correction by the ilizarov method. The Journal of Bone \& Joint Surgery, 80, 762-765. http://dx.doi.org/10.1302/0301-620X.80B5.8839

[8] Clark, D.I., Chell, J. and Davis, T.R. (1998) Pollicisation of the index finger. A 27-year follow-up study. The Journal of Bone \& Joint Surgery, 80, 631-635. http://dx.doi.org/10.1302/0301-620X.80B4.8613

[9] Tenkir, A. and Teshome, S. (2010) Golts syndrome (focal dermal hypoplasia) with unilateral ocular, cutaneous and skeletal feature, case report. BMC Ophthalmology, 10, 28.

[10] Menelaus, M.B. (1976) Radial club hand with absence of the biceps muscle treated by centralization of the ulnar and triceps transfer. Report of two cases. The Journal of Bone \& Joint Surgery, 5, 488-491. 